\title{
Estimate of Impact on the Oral Health-Related Quality of Life of Older Thai People by the Provision of Dentures through the Royal Project
}

\author{
Patcharawan Srisilapanan, ${ }^{1}$ Narumanas Korwanich, ${ }^{1}$ Sutha Jienmaneechotchai, ${ }^{2}$ \\ Supranee Dalodom, ${ }^{2}$ Nontalee Veerachai, ${ }^{2}$ Warangkana Vejvitee, ${ }^{2}$ and Jeffrey Roseman ${ }^{3}$ \\ ${ }^{1}$ Center of Excellence in Dental Public Health, Faculty of Dentistry, Chiang Mai University, Chiang Mai 50200, Thailand \\ ${ }^{2}$ Bureau of Dental Health, Ministry of Public Health, Nonthaburi 11000, Thailand \\ ${ }^{3}$ Department of Epidemiology, UAB School of Public Health, University of Alabama, Birmingham, AL 35294-0022, USA
}

Correspondence should be addressed to Patcharawan Srisilapanan; patcharawana@gmail.com

Received 10 March 2016; Revised 23 May 2016; Accepted 1 June 2016

Academic Editor: Claudio Rodrigues Leles

Copyright (C) 2016 Patcharawan Srisilapanan et al. This is an open access article distributed under the Creative Commons Attribution License, which permits unrestricted use, distribution, and reproduction in any medium, provided the original work is properly cited.

\begin{abstract}
Purpose. To estimate the impact of the provision of dentures to Thai older people by the Royal Project on their oral health-related quality of life. Methods. A purposive cross-sectional study of a sample of 812 subjects was conducted. The Oral Impacts on Daily Performances (OIDP) measure was used to assess the oral health-related quality of life. Results. Four groups of older people with different tooth types were studied. 216 (26.6\%) had natural teeth (NT). 189 (23.3\%) had natural and replaced teeth (NRT). 167 (20.6\%) had below the minimum number of teeth but had no dentures (Edent) and 240 were edentate with complete dentures provided by the Royal Project (ECD) (29.6\%). Overall, 36.5\% had at least one oral impact. Eating was the most affected oral impact. When compared to the group with natural teeth (NT), the Edent group was significantly more likely to report having impacts on eating $\mathrm{OR}=6.5(3.9-10.9)$, speaking clearly $\mathrm{OR}=43.7$ (12.7-15.07), emotional stability $\mathrm{OR}=16.5$ (6.0-45.6), and social contacts $\mathrm{OR}=4.6(2.2-9.5)(p<0.001)$. Conclusion. Those who are edentulous are much more likely to have an oral impact on their daily performances than those provided dentures. Provision of dentures may lead to improvement of considerable oral impacts.
\end{abstract}

\section{Background}

In 2005, Thailand reached the aging society whereby ten percent of the total population were sixty years of age or older [1]. This proportion is expected to increase to $20 \%$ by 2025 [2]. Consequently, aging has become an important issue for health and oral health care providers. The World Health Organization (WHO) has included oral health as a component of active aging. In the WHO policy framework of active aging, maintaining natural teeth throughout life could promote health [3]. Therefore, having good oral health should contribute to older people's health and quality of life.

Loss of teeth is the most common dental problem among the older people [4-6]. Having missing teeth has a measurable impact on daily living especially in older people [710]. Denture status has been related to quality of life [11, 12].
Subjects with missing teeth who did not wear dentures had lower oral health-related quality of life scores than those who wore removable or complete dentures [12]. However, those studies which were performed in Germany included a wide age range from 16 to 79 years old and were not aimed at studying the impact of the provision of dentures on the oral health-related quality of life in an older age Asian group.

The most recent Thai National Oral Health Survey reported that $7.2 \%$ of people aged 60 and above were edentulous [13]. To improve inequity in access to oral care and to improve the oral health of the Thai older people, the Thai Government launched the Royal Denture Project to provide free complete dentures or removable dentures to those who needed them. Older people who participated in the Royal Denture Project were provided with dentures by dentists. 
National guidelines to make the dentures were developed by an expert panel of prosthodontists from Thai dental schools.

There have been a number of studies showing improved oral health quality of life after the provision of dentures. According to other studies, wearing dentures helps rehabilitate the oral health status for the older people, and it improves the chewing ability and makes oral health functions better. This therefore improves their quality of life [14-18]. Ettinger also found that good-quality complete dentures increased chewing ability [19]. The improvement of the quality of life after receiving new dentures was also reported in a study of French older people [20] and a Canadian study [9]; however, no studies have involved Asian samples or places where the dentures were provided by a government.

This study was conducted with the objective of assessing the relationship between dental status and oral health-related quality of life in older Thai people.

\section{Methods}

This cross-sectional study was approved by the Ethical Committee of the Faculty of Dentistry, Chiang Mai University.

\section{Subjects}

Subjects were independently living older persons aged 60 years and above. They were only included in the study if they had adequate general health; that is, they could have a systemic disease but were able to live independently. They were excluded if they had any soft tissue oral lesions, had oral cancer, had taken any medicine which affected salivary secretion, or had any history of an accident to the head and neck area. Participants provided informed consent before inclusion.

\section{Study Sites}

Five cities were purposively selected to represent different parts of Thailand: Chiang Mai for the upper northern region, Phitsanulok for the lower northern region, Songkhla for the southern region, Chaiyaphum for the northeastern region, and Bangkok for the metropolitan area. At each site, approximately 30-40 subjects were recruited for each group. A total of 120 to 180 participants were recruited from each study site.

\section{Subject Recruitment}

The ECD and NRT were purposively sampled from those who had undergone treatment for complete dentures or acrylic partial dentures under the Royal Denture Project. Subjects in ECD group were those who had worn their new dentures for at least one year prior to clinical examination and the interview period. NRT subjects were those who had at least 16 missing teeth and had removable partial dentures made under the Royal Project to replace missing teeth at least one year prior to the study. All remaining teeth of the NRT subjects were functional. The other two groups of subjects (Edent and NT) were recruited from older people who resided in the same community as the ECD and NRT groups and were of comparable economic status as those two groups. The edentates (Edent) were persons who had become edentate for one year or more prior to the study period but had not had dentures made. The NT group subjects were those who had at least 4 occluding pairs of posterior teeth, had no or minimal mobility, and were free from the need for emergency treatment and pain. The NT and Edent groups did not have the history of wearing dentures.

\section{Clinical Examination}

All subjects were clinically examined by trained dentists. Training sessions for clinical assessment were organized to calibrate the examiners. All clinical examinations were done under natural light in community settings. The clinical data assessed for dentate subjects included numbers and status of natural teeth, types of dentures, and occluding posterior pairs of teeth in the premolar and molar areas. Denture-bearing areas in edentate participants were examined for the presence of lesions, condition of dentures, and numbers of occluding posterior pairs.

\section{Interview and the Assessment of Oral Impacts on Quality of Life}

Prior to the assessment for the impact on their quality of life in all subjects, cognitive impairment was assessed using the Mini-Mental State Examination (MMSE) which had been translated into Thai $[21,22]$. Only those who scored $\geq 18$ on MMSE were included in the study. The face-to-face interviews were conducted by trained interviewers to collect data on basic sociodemographic variables, such as age, gender, and level of education. Oral health-related quality of life (OHRQoL) data were assessed using the Oral Impacts on Daily Performances (OIDP) indicator. This OHRQoL index has been widely accepted and previously translated and employed in Thai populations [7, 23]. The interview was conducted by a team of interviewers who had previously undergone 2-day training and calibration course on the OIDP measure.

\section{Calculation of the OIDP Score}

The OIDP instrument is a composite OHRQoL measure. It is a theoretically sound, relatively brief instrument that attempts to measure oral impacts which can seriously affect a person's daily life. In this study, we focused on 8 basic daily life activities and behaviors. The OIDP instrument measures both the frequency and the severity of impacts on daily activities affected by the oral conditions in the last 6 months. This OIDP indicator provides scores ranging from 0 to 25 for each daily activity and from 0 to 200 for overall impact on daily performance. In addition to the OIDP scores, the intensity of the oral impacts was calculated. Intensity was defined according to the highest daily performance score among the eight performances, which were classified into five levels: very little, little, moderate, severe, and very severe. The intensity illustrates how severe the impacts of mouth were on daily life [24]. 
TABLE 1: Comparisons of prevalence and total mean OIDP score of oral impacts on daily performances between the groups.

\begin{tabular}{|c|c|c|c|c|c|c|c|}
\hline \multirow{3}{*}{ Oral impacts } & \multicolumn{6}{|c|}{ Subjects with different dental status } & \multirow{3}{*}{$p$ value $^{*}$} \\
\hline & Total prevalence & $\begin{array}{l}\text { Edentate } \\
\text { (Edent) }\end{array}$ & $\begin{array}{l}\text { Complete } \\
\text { denture } \\
(\mathrm{ECD})\end{array}$ & $\begin{array}{l}\text { Natural and } \\
\text { replaced } \\
\text { teeth }(\mathrm{NRT})\end{array}$ & $\begin{array}{l}\text { Natural } \\
\text { teeth (NT) }\end{array}$ & $\begin{array}{l}\text { Total mean } \\
\text { OIDP score }\end{array}$ & \\
\hline & $n(\%)$ & $n(\%)$ & $n(\%)$ & $n(\%)$ & $n(\%)$ & Mean $( \pm S D)$ & \\
\hline Overall impacts & $297(36.6)$ & $114(68.3)$ & $68(28.3)$ & $60(31.7)$ & $55(25.5)$ & & \\
\hline \multicolumn{8}{|l|}{ Physical performances } \\
\hline Eating & $220(27.1)$ & $94(56.3)$ & $48(20.0)$ & $41(21.7)$ & $37(17.2)$ & $2.8( \pm 6.1)$ & $<0.001$ \\
\hline Speaking clearly & 97 (11.9) & $59(35.3)$ & $17(7.1)$ & $18(9.5)$ & $3(1.4)$ & $1.0( \pm 3.9)$ & $<0.001$ \\
\hline Cleaning mouth & $37(4.6)$ & $14(8.4)$ & $8(3.3)$ & $4(2.1)$ & $11(5.1)$ & $0.4( \pm 2.4)$ & 0.027 \\
\hline Doing light activities & $10(1.2)$ & $4(2.4)$ & $3(1.3)$ & $1(0.5)$ & $2(0.9)$ & $0.1( \pm 1.1)$ & 0.425 \\
\hline \multicolumn{8}{|l|}{ Psychological performances } \\
\hline Sleeping and relaxing & $49(6.0)$ & $12(7.2)$ & $10(4.2)$ & $14(7.4)$ & $13(6.0)$ & $0.4( \pm 2.3)$ & 0.403 \\
\hline Smiling & $25(3.1)$ & $23(13.8)$ & $1(0.4)$ & $1(0.5)$ & $0(0.0)$ & $0.3( \pm 2.3)$ & $<0.001$ \\
\hline Emotional stability & $74(9.1)$ & $35(21.0)$ & $10(4.2)$ & $16(8.5)$ & $13(6.0)$ & $0.8( \pm 3.2)$ & $<0.001$ \\
\hline \multicolumn{8}{|l|}{ Social performances } \\
\hline Social contact & $49(6.0)$ & $40(24.0)$ & $1(0.4)$ & $3(1.6)$ & $5(2.3)$ & $0.6( \pm 3.1)$ & $<0.001$ \\
\hline Total mean OIDP score (mean \pm SD) & & $9.6( \pm 13.6)$ & $1.6( \pm 4.5)$ & $1.9( \pm 5.0)$ & $1.4( \pm 4.2)$ & $3.3( \pm 8.0)$ & \\
\hline
\end{tabular}

${ }^{*} p<0.05$, Chi-square.

\section{Statistical Analysis}

Descriptive statistics were used to describe the prevalence, the severity, and the intensity of Oral Impacts on Daily Performances among subjects with different dental status. Odds ratio and multivariate logistic regression analysis were used to test significance of the independent variables and the difference in the overall oral impact scores in groups with different dental status. Unadjusted odds ratios were calculated by comparing proportion of subjects who reported suffering in each daily life activity among Edent, ECD, and NRT groups to those in the reference NT group. Then, an adjusted odds ratio was calculated where sex, age, marital status, education level, and systemic disease were added to the calculation. 95\% confidence intervals and $p$ values were also computed and presented.

\section{Sample Size}

Subjects were categorized into four groups by dental status: edentulous but no denture (Edent), edentulous with complete dentures (ECD), with natural and replaced teeth (NRT), and with only natural teeth (NT). Sample size calculation was aimed at detecting differences of OIDP scores among the 4 study groups. Using the standard deviation of the total OIDP scores from a previous study [7] under conditions of a $95 \%$ confidence interval and $85 \%$ power of test, the minimum sample size was computed to be 160 for each group.

\section{Results}

All 848 subjects approached consented to participate in the study. Three subjects were excluded as their MMSE scores were $\leq 18$. Thirty-three subjects were below 60 years of age and did not complete the clinical examination or the interview. Only 812 subjects fully participated in the study: 353 (43.5\%) males and 459 (56.5\%) females. The average age of subjects was $69.8 \pm 6.1$ years. 216 subjects $(26.6 \%)$ had natural teeth (NT); 189 (23.3\%) had natural and replaced teeth (NRT); 167 (20.6\%) were edentate but did not have a denture (Edent); and 240 (29.6\%) wore complete dentures (ECD). There were more females than males in all groups.

Table 1 presents the impact of oral health on different daily performances. Among all subjects, approximately a third (36.6\%) had at least one OIDP impact which affected their daily performances in the past 6 months. Eating was the most commonly impacted performance $(27.1 \%)$. The average total OIDP scores for ECD were $1.6 \pm 4.5$, similar to $1.9 \pm 5.0$ for NRT and $1.4 \pm 4.2$ for NT groups, but considerably less than $9.6 \pm 13.6$ for Edent. Eating was the most frequently affected oral performance in all four groups. The mean total OIDP score for eating was the highest of all oral impacts. The other two most frequently influenced activities were speaking clearly (11.9\%) and emotional stability (9.2\%). Doing light activities was the performance least affected by oral status $(1.2 \%)$.

The subjects in four different dental status groups reported significant differences in oral impacts on eating, speaking clearly, cleaning mouth, smiling, emotional stability, and social contacts $(p<0.05)$. The Edent group, compared to the other three groups, reported the highest proportion of oral impacts on all eight performances, significantly so with respect to eating, speaking clearly, cleaning mouth, smiling, emotional stability, and social contact (Table 1).

In the analysis for severity and intensity of the oral impacts, among those who reported having any impacts, 
TABLE 2: Intensity of oral impacts among 812 Thai older people.

\begin{tabular}{|c|c|c|c|c|c|c|}
\hline \multirow{2}{*}{ Oral impacts } & \multirow{2}{*}{$\begin{array}{c}\text { Subjects } \\
\text { with } \\
\text { impacts } \\
n(\%)\end{array}$} & \multicolumn{5}{|c|}{$\begin{array}{c}\text { Intensity } \\
n(\%)\end{array}$} \\
\hline & & Very little & Little & Moderate & Severe & Very severe \\
\hline Overall impacts & $297(100)$ & 59 (19.7) & $60(20.2)$ & $84(28.3)$ & $41(13.8)$ & $53(17.8)$ \\
\hline \multicolumn{7}{|l|}{ Physical performances } \\
\hline Eating & $220(100)$ & $32(14.5)$ & $43(19.5)$ & $67(30.5)$ & $38(17.3)$ & $40(18.2)$ \\
\hline Speaking clearly & $97(100)$ & $26(26.8)$ & $18(18.6)$ & $31(32.0)$ & $6(6.2)$ & $16(16.5)$ \\
\hline Cleaning mouth & $37(100)$ & $7(18.9)$ & $8(21.6)$ & $12(32.4)$ & $6(16.2)$ & $4(10.8)$ \\
\hline Doing light activities & $10(100)$ & $2(20.0)$ & $0(0.0)$ & $6(60.0)$ & $1(10.0)$ & $1(10.0)$ \\
\hline \multicolumn{7}{|l|}{ Psychological performances } \\
\hline Sleeping and relaxing & $49(100)$ & $15(30.6)$ & $11(22.4)$ & $13(26.5)$ & $6(12.2)$ & $4(8.2)$ \\
\hline Smiling & $25(100)$ & $3(12.0)$ & $3(12.0)$ & $12(48.0)$ & $2(8.0)$ & $5(20.0)$ \\
\hline Emotional stability & $74(100)$ & $14(18.9)$ & $17(23.0)$ & $22(29.7)$ & $13(17.6)$ & $8(10.8)$ \\
\hline \multicolumn{7}{|l|}{ Social performances } \\
\hline Social contact & $49(100)$ & $9(18.4)$ & $8(16.3)$ & $19(38.8)$ & $1(2.0)$ & $12(24.5)$ \\
\hline
\end{tabular}

$31.7 \%$ reported impacts of severe or very severe intensity; $40.1 \%$ reported that their impacts were of only little or very little intensity (Table 2). When analyzing the impact on each performance separately, the top three impacts reported to be severely affected were eating (35.5\%), emotion (28.4\%), and smiling (28.0\%). Doing light activities was the least severely affected $(20.0 \%)$. The top three impacts reported to be very severely affected were social contact (24.5\%), smiling (20.0\%), and eating (18.2\%).

Table 3 presents the results of a multivariable logistic regression analysis. The odds ratios of Edent, ECD, and NRT reporting having oral impacts on each performance were compared to the NT group in both unadjusted and adjusted models. In both the unadjusted and adjusted models, the overall impact and specific significant oral impacts on eating, speaking clearly, emotional stability, and social contacts were 6.5 (3.9-10.9), 43.7 (12.7-15.1), 16.5 (6.0-45.6), and 4.6 (2.29.5) times more in Edent subjects compared to their counterparts in the NT group. The ECD and NRT subjects were only significantly more likely to report impacts on speaking than the NT group $(\mathrm{OR}=5.4(1.6-18.9)$ and $7.5(2.2-25.6))$.

\section{Discussion}

More than one-third of the subjects with all types of dental status $(36.5 \%)$ reported that they had experienced one or more oral impacts which affected their daily life. As the samples from this study were not representative of the whole population of Thai older people, it is not appropriate to directly compare the present findings to other studies. However, it is worth noting that the range of oral impacts using the same OHRQoL index for assessment was lower than in other studies, which ranged from $39.1 \%$ to $62.9 \%$ [25-27] although the proportion of subjects who reported severe or very severe oral impacts was similar to that reported in a group of Northern Thai older people (39.1\%) [7]. The strong Buddhist belief may be one of the reasons to explain the lower expression of impacts from oral conditions in our sample. In Thailand, $94.6 \%$ of the population are Buddhist [28]. Thais believe that aging is the transiency of life. Under this belief, they may accept the changes and impacts from health condition as part of normal aging phenomena. Losing teeth and changes due to an oral condition are accepted as normal. Therefore, any problems from oral conditions may not be seen as having much effect on their lives as in other populations.

The intensity analysis illustrates how severe the impacts of oral symptoms were on their daily lives. Although the prevalence of the oral impacts was relatively low, many reported their impacts as being from severe to very severe. This finding suggests a strong need to intervene to address oral health issues of the older people, since they may be unlikely to seek treatment for something they believe is normal.

When comparing the oral impacts among older people with different dental status, the group with the highest proportion to report having oral impacts was the edentate group. Among the ECD group, only speaking differed significantly from NT group. These results are consistent with other studies reporting that wearing dentures improves quality of life [14-18]. Ettinger also reported that good-quality complete dentures increased chewing ability [19]. The improvement of the quality of life after receiving new dentures was also reported in a study of French older people [20] and a Canadian study [14]. This suggests that the provision of dentures to older Thai people greatly improves their oral health quality of life, almost to the level of those with adequate natural teeth. In addition, dental status not only can affect the ability to eat but also affects nutrient intake and hence can compromise overall health and well-being [29-31].

Although this study provides evidence for the benefit of providing dentures to the edentulous population as done in the Royal Denture Project, it also provides evidence for the importance of maintaining teeth throughout life. Providing 
TABLE 3: Unadjusted and adjusted odds ratio (95\% confidence interval) of overall oral impacts in groups with different dental status.

\begin{tabular}{|c|c|c|c|c|}
\hline & $\begin{array}{l}\text { Unadjusted } \\
\text { odds ratio }\end{array}$ & $p$ value & $\begin{array}{l}\text { Adjusted } \\
\text { odds ratio }\end{array}$ & $p$ value \\
\hline \multicolumn{5}{|c|}{ Overall impacts ${ }^{* *}$} \\
\hline Edent & $6.6(4.1-10.3)$ & $<0.001$ & $8.1(4.8-13.5)$ & $<0.001$ \\
\hline ECD & $1.2(0.8-1.7)$ & 0.492 & $1.2(0.8-1.8)$ & 0.475 \\
\hline NRT & $1.4(0.9-2.1)$ & 0.171 & $1.3(0.9-2.0)$ & 0.201 \\
\hline \multicolumn{5}{|c|}{ Physical performances } \\
\hline \multicolumn{5}{|l|}{ Eating } \\
\hline Edent & $6.4(4.0-10.2)$ & $<0.001$ & $6.5(3.9-10.9)$ & $<0.001$ \\
\hline ECD & $1.2(0.7-1.9)$ & 0.432 & $1.1(0.7-1.8)$ & 0.720 \\
\hline NRT & $1.3(0.8-2.2)$ & 0.246 & $1.2(0.7-2.0)$ & 0.507 \\
\hline \multicolumn{5}{|c|}{ Speaking clearly } \\
\hline Edent & $38.8(11.9-126.6)$ & $<0.001$ & $43.7(12.7-15.07)$ & $<0.001$ \\
\hline $\mathrm{ECD}$ & $5.4(1.6-18.7)$ & 0.008 & $4.9(1.4-17.7)$ & 0.008 \\
\hline NRT & $7.5(2.2-25.8)$ & 0.001 & $7.7(2.2-27.2)$ & $<0.001$ \\
\hline \multicolumn{5}{|c|}{ Cleaning mouth } \\
\hline Edent & $1.7(0.7-3.8)$ & 0.205 & $2.3(0.9-5.7)$ & 0.205 \\
\hline ECD & $6.4(0.2-1.6)$ & 0.346 & $0.6(0.2-1.5)$ & 0.346 \\
\hline NRT & $0.4(0.1-1.3)$ & 0.123 & $0.4(0.1-1.3)$ & 0.14 \\
\hline \multicolumn{5}{|c|}{ Doing light activities } \\
\hline Edent & $2.6(0.5-14.5)$ & 0.268 & $3.9(0.6-27.0)$ & 0.268 \\
\hline ECD & $1.3(0.2-8.1)$ & 0.741 & $1.2(0.2-8.7)$ & 0.864 \\
\hline NRT & $0.6(0.5-6.3)$ & 0.646 & $0.7(0.6-8.5)$ & 0.788 \\
\hline \multicolumn{5}{|c|}{ Psychological performances ${ }^{* * *}$} \\
\hline \multicolumn{5}{|c|}{ Sleeping and relaxing } \\
\hline Edent & $1.3(0.6-2.9)$ & 0.497 & $1.4(0.6-3.4)$ & 0.412 \\
\hline ECD & $0.4(0.3-1.6)$ & 0.369 & $0.7(0.3-1.8)$ & 0.369 \\
\hline NRT & $1.2(0.6-2.7)$ & 0.577 & $1.3(0.6-2.9)$ & 0.529 \\
\hline \multicolumn{5}{|c|}{ Emotion stability } \\
\hline Edent & $13.4(5.1-34.8)$ & $<0.001$ & $16.5(6.0-45.6)$ & $<0.001$ \\
\hline ECD & $0.2(0.0-1.5)$ & 0.115 & $0.2(0.0-1.9)$ & 0.148 \\
\hline NRT & $0.7(0.2-2.9)$ & 0.602 & $0.8(0.2-3.5)$ & 0.797 \\
\hline \multicolumn{5}{|c|}{ Social performances } \\
\hline \multicolumn{5}{|c|}{ Social contact } \\
\hline Edent & $4.3(2.2-8.5)$ & $<0.001$ & $4.6(2.2-9.5)$ & $<0.001$ \\
\hline ECD & $0.7(0.3-1.6)$ & 0.369 & $0.7(0.3-1.8)$ & 0.506 \\
\hline NRT & $1.4(0.7-3.1)$ & 0.343 & $1.2(0.6-2.8)$ & 0.551 \\
\hline
\end{tabular}

* Adjusted with sex, age, marital status, education level, income, and systemic disease.

** Reference group: natural teeth group.

${ }^{* * *}$ As no subjects in a reference group reported impact on smiling, the odds ratios were not calculated in this performance.

dentures after tooth loss consumes the dentist's time and is costly. In Thailand, the aging population is projected to increase dramatically [32]. The dental manpower will not be able to meet the demand for oral rehabilitation in the future. Therefore, oral health promotion to promote proper oral health care at an earlier stage should be the high priority for the dental public health personnel.

\section{Limitation of the Study}

The cross-sectional design in this study could not allow us to make a direct conclusion that providing dentures to those who were in need could improve their quality of life. While our findings determine a relationship between being provided with dentures and having a higher quality of life, more research needs to be carried out on a longitudinal basis.

\section{Conclusions}

The results suggest that among older Thai people those provided with dentures had important impacts on their oral health quality of life, which provides support for the government effort to provide dentures. 


\section{Competing Interests}

The authors declare that there are no competing interests regarding the publication of this paper.

\section{Authors' Contributions}

Each of the authors was involved in designing the study. Patcharawan Srisilapanan supervised the project and carried out the design, analysis, and writing of the paper. Narumanas Korwanich analyzed the data and carried out the writing of the paper. Sutha Jienmaneechotchai supervised the project and gave comment on interpretation. Supranee Dalodom, Nontalee Veerachai, and Warangkana Vejvitee collected the data and assisted in the writing. Jeffrey Roseman assisted in data analysis and the writing. All the authors have read and approved the final paper.

\section{Acknowledgments}

This research was supported by the Department of Health, Ministry of Public Health. The authors would like to thank Late Professor Aubrey Sheiham for his valuable comments on revisions of the paper. And they also wish to thank all the dentists in the community hospitals and the Provincial Public Health Office that participated in this study for their kind cooperation and their help and contribution. Special thanks are due to the dental and health personnel at each local study site for their kind assistance.

\section{References}

[1] P. Limpawattana, S. Sutra, Y. Thavornpitak, K. Wirasorn, J. Chindaprasirt, and P. Mairieng, "Health situation analysis of hospitalized Thai older persons in the year 2010," Journal of the Medical Association of Thailand, vol. 95, supplement 7, pp. S81S86, 2012.

[2] Bureau of Empowerment for Older Persons, Office of Welfare Promotion: Protection, and Empowerment of Vulnerable Group, Ministry of Social Development and Human Security, Report on Thailand Elderly Situation, 2004 (Thai).

[3] World Health Organization, "Active ageing: a policy framework," Aging Male, vol. 24, pp. 1-37, 2002.

[4] T. Hiidenkari, T. Parvinen, and H. Helenius, "Missing teeth and lost teeth of adults aged 30 years and over in south-western Finland," Community Dental Health, vol. 13, no. 4, pp. 215-222, 1996.

[5] P. E. Petersen, “The World Oral Health Report 2003: continuous improvement of oral health in the 21st century-the approach of the WHO Global Oral Health Programme," Community Dentistry and Oral Epidemiology, vol. 31, supplement 1, pp. 324, 2003.

[6] T. C. Nguyen, D. J. Witter, E. M. Bronkhorst, N. B. Truong, and N. H. J. Creugers, "Oral health status of adults in Southern Vietnam-a cross-sectional epidemiological study," BMC Oral Health, vol. 13, no. 1, article 2, pp. 1-11, 2010.

[7] P. Srisilapanan and A. Sheiham, "Assessing the difference between sociodental and normative approaches to assessing prosthetic dental treatment needs in dentate older people," Gerodontology, vol. 18, no. 1, pp. 25-34, 2001.
[8] D. Locker, D. Matear, and H. Lawrence, "General health status and changes in chewing ability in older Canadians over seven years," Journal of Public Health Dentistry, vol. 62, no. 2, pp. 7077, 2002.

[9] P. F. Allen, "Assessment of oral health related quality of life," Health and Quality of Life Outcomes, vol. 1, article 40, 2003.

[10] R. Perera and L. Ekanayake, "Oral impacts and their association with tooth loss in Sri Lankan adults," Community Dental Health, vol. 29, no. 3, pp. 214-218, 2012.

[11] M. T. John, L. LeResche, T. D. Koepsell, P. Hujoel, D. L. Miglioretti, and W. Micheelis, "Oral health-related quality of life in Germany," European Journal of Oral Sciences, vol. 111, no. 6, pp. 483-491, 2003.

[12] M. T. John, T. D. Koepsell, P. Hujoel, D. L. Miglioretti, L. LeResche, and W. Micheelis, "Demographic factors, denture status and oral health-related quality of life," Community Dentistry and Oral Epidemiology, vol. 32, no. 2, pp. 125-132, 2004.

[13] Dental Public Health Bureau, Department of Health, Ministry of Public Health: The 7th Thailand National Oral Health Survey (in Thai), 2013.

[14] I. Appollonio, C. Carabellese, A. Frattola, and M. Trabucchi, "Dental status, quality of life, and mortality in an older community population: a multivariate approach," Journal of the American Geriatrics Society, vol. 45, no. 11, pp. 1315-1323, 1997.

[15] D. Locker, D. Matear, M. Stephens, and A. Jokovic, "Oral healthrelated quality of life of a population of medically compromised elderly people," Community Dental Health, vol. 19, no. 2, pp. 9097, 2002.

[16] G. H. Gilbert, X. Meng, R. P. Duncan, and B. J. Shelton, "Incidence of tooth loss and prosthodontic dental care: effect on chewing difficulty onset, a component of oral health-related quality of life," Journal of the American Geriatrics Society, vol. 52, no. 6, pp. 880-885, 2004.

[17] J. S. Ellis, N. D. Pelekis, and J. M. Thomason, "Conventional rehabilitation of edentulous patients: the impact on oral healthrelated quality of life and patient satisfaction," Journal of Prosthodontics, vol. 16, no. 1, pp. 37-42, 2007.

[18] J. Montero, J. F. López, M. P. Galindo, P. Vicente, and M. Bravo, "Impact of prosthodontic status on oral wellbeing: a cross-sectional cohort study," Journal of Oral Rehabilitation, vol. 36, no. 8, pp. 592-600, 2009.

[19] R. L. Ettinger, "Changing dietary patterns with changing dentition: how do people cope?" Special Care in Dentistry, vol. 18, no. 1, pp. 33-39, 1998.

[20] E. Nicolas, J.-L. Veyrune, and C. Lassauzay, "A Six-month assessment of oral health-related quality of life of complete denture wearers using denture adhesive: a pilot study," Journal of Prosthodontics, vol. 19, no. 6, pp. 443-448, 2010.

[21] M. F. Folstein, S. E. Folstein, and P. R. McHugh, “'Mini-mental state. A practical method for grading the cognitive state of patients for the clinician," Journal of Psychiatric Research, vol. 12, no. 3, pp. 189-198, 1975.

[22] P. Srisilapanan, Assessing dental treatment needs in older people: a socio-dental approach [Ph.D. thesis], London University, Epidemiology and Public Health Department, London, UK, 1997.

[23] S. Adulyanon, J. Vourapukjaru, and A. Sheiham, "Oral impacts affecting daily performance in a low dental disease Thai population," Community Dentistry and Oral Epidemiology, vol. 24, no. 6, pp. 385-389, 1996.

[24] S. Gherunpong, G. Tsakos, and A. Sheiham, "The prevalence and severity of oral impacts on daily performances in Thai 
primary school children," Health and Quality of Life Outcomes, vol. 2, article 57, 2004.

[25] G. Tsakos, W. Marcenes, and A. Sheiham, "Cross-cultural differences in oral impacts on daily performance between Greek and British older adults," Community Dental Health, vol. 18, no. 4, pp. 209-213, 2001.

[26] I. A. Kida, A. N. Åstrøm, G. V. Strand, J. R. Masalu, and G. Tsakos, "Psychometric properties and the prevalence, intensity and causes of oral impacts on daily performance (OIDP) in a population of older Tanzanians," Health and Quality of Life Outcomes, vol. 4, article 56, 2006.

[27] S.-H. Jung, J.-I. Ryu, G. Tsakos, and A. Sheiham, "A Korean version of the Oral Impacts on Daily Performances (OIDP) scale in elderly populations: validity, reliability and prevalence," Health and Quality of Life Outcomes, vol. 6, article 17, 2008.

[28] National Statistical Office, The 2010 Population and Housing Census, National Statistical Office, Bangkok, Thailand, 2011.

[29] E. Budtz-Jørgensen, J.-P. Chung, and C.-H. Rapin, "Nutrition and oral health," Best Practice and Research in Clinical Gastroenterology, vol. 15, no. 6, pp. 885-896, 2001.

[30] A. Sheiham and J. Steele, "Does the condition of the mouth and teeth affect the ability to eat certain foods, nutrient and dietary intake and nutritional status amongst older people?" Public Health Nutrition, vol. 4, no. 3, pp. 797-803, 2001.

[31] A. Sheiham, J. G. Steele, W. Marcenes, G. Tsakos, S. Finch, and A. W. G. Walls, "Prevalence of impacts of dental and oral disorders and their effects on eating among older people; a national survey in Great Britain," Community Dentistry and Oral Epidemiology, vol. 29, no. 3, pp. 195-203, 2001.

[32] United Nations Population Fund, Population Ageing in Thailand: Prognosis and Policy Response, United Nations Population Fund, Bangkok, Thailand, 2006. 


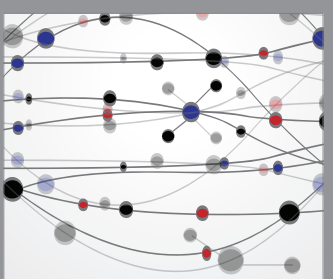

The Scientific World Journal
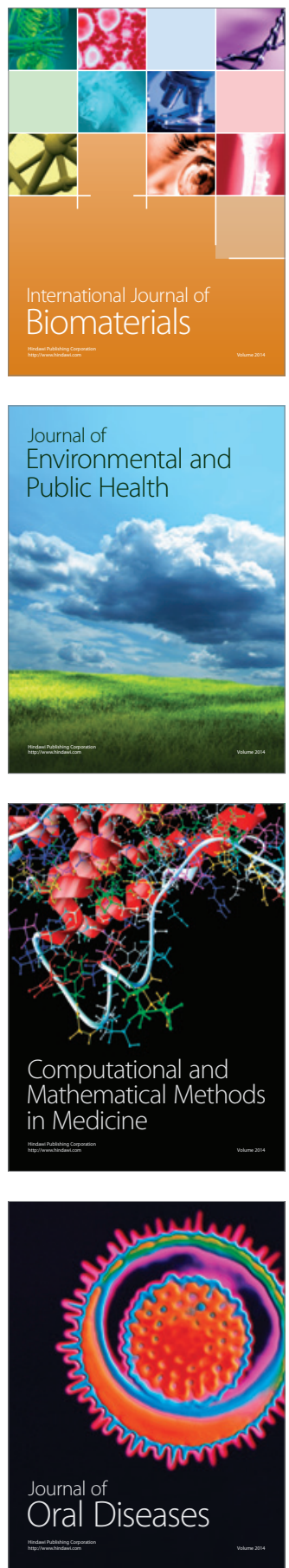
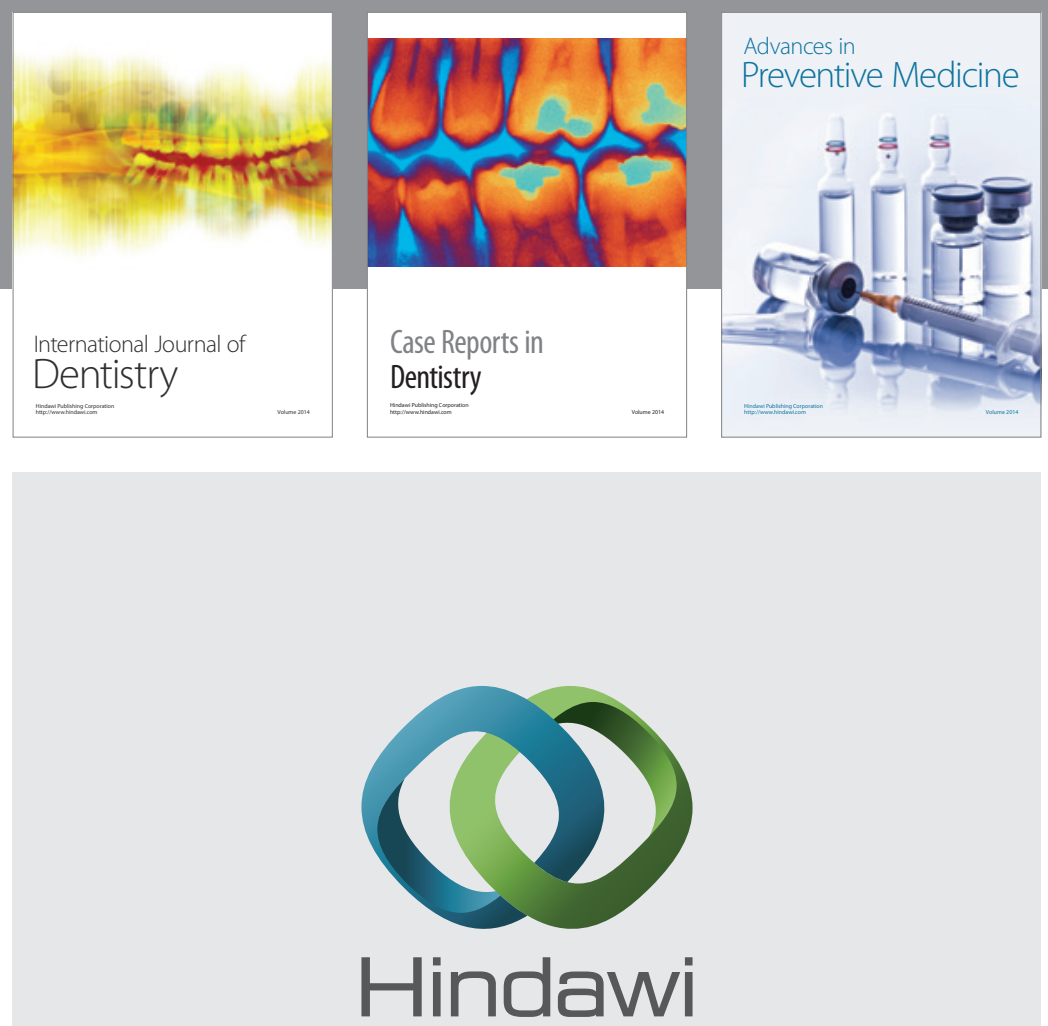

Submit your manuscripts at

http://www.hindawi.com
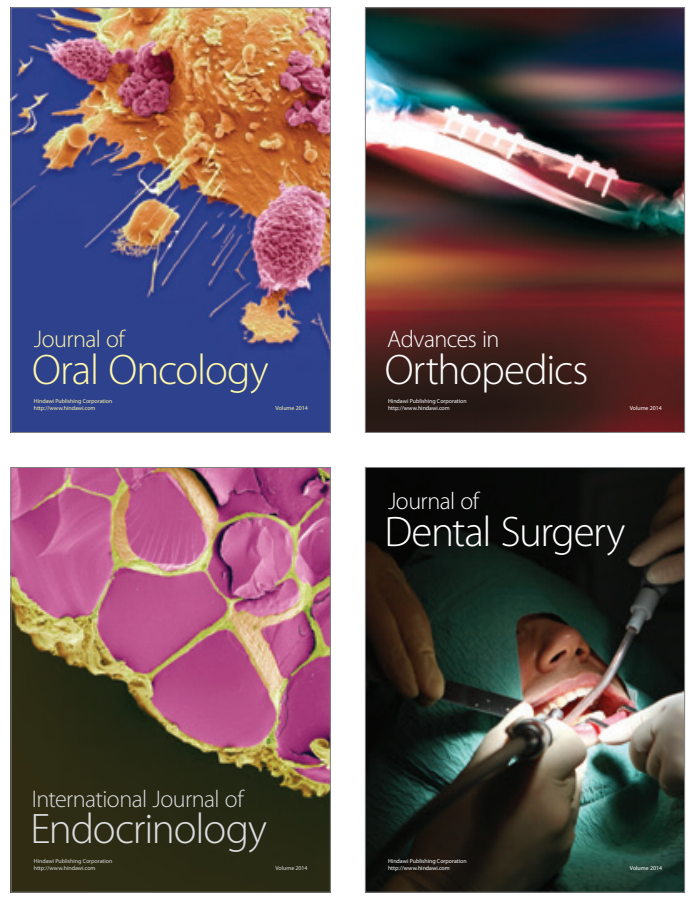
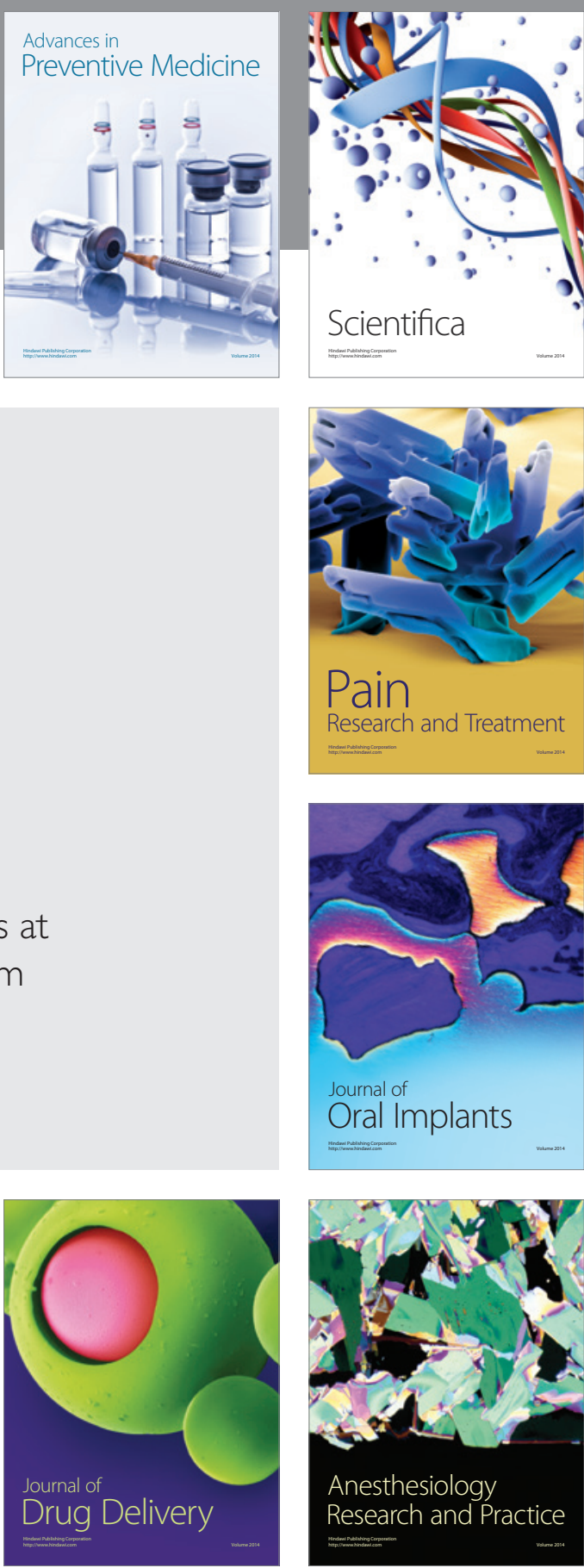

Scientifica
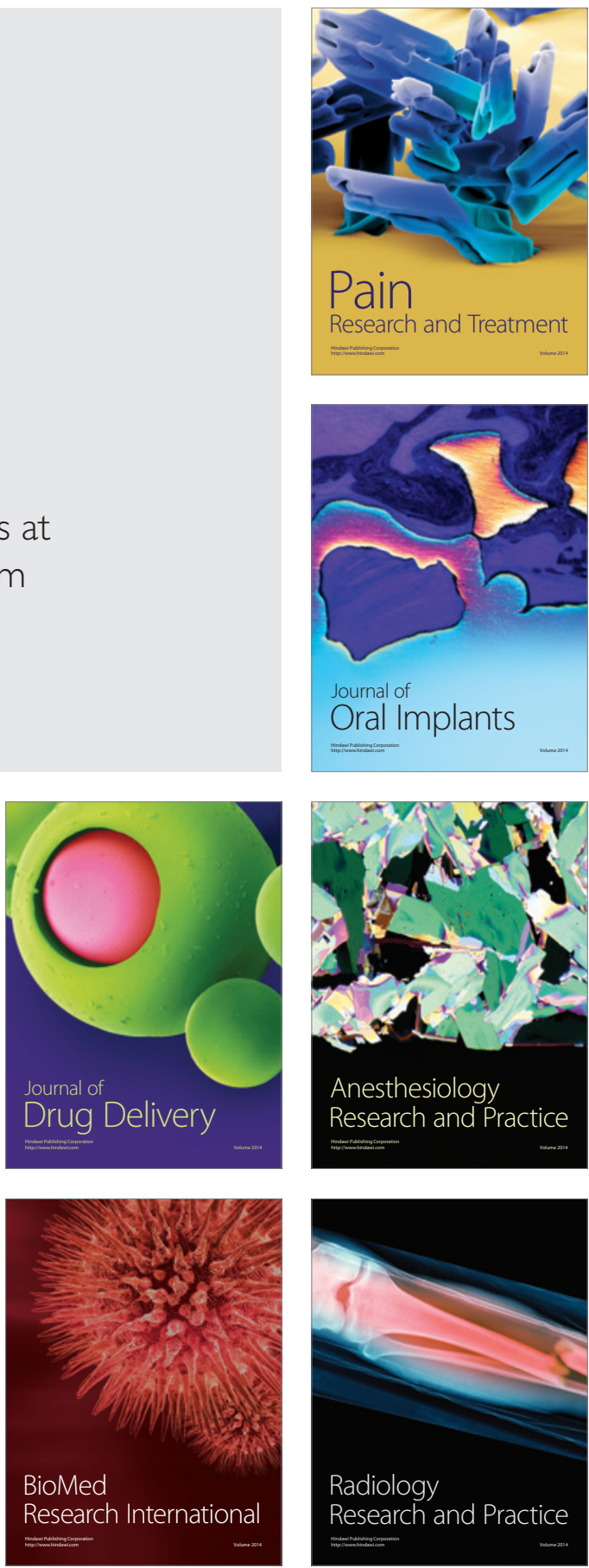